\title{
ABC-finder: A containerized web server for the identification and topology prediction of $\mathrm{ABC}$ proteins
}

Poonam Vishwakarma ${ }^{1 \#}$, Naveen Kumar Meena ${ }^{1 \#}$, Rajendra Prasad $^{2 *}$, Andrew M. Lynn $^{1 *}$ and Atanu Banerjee ${ }^{2 *}$

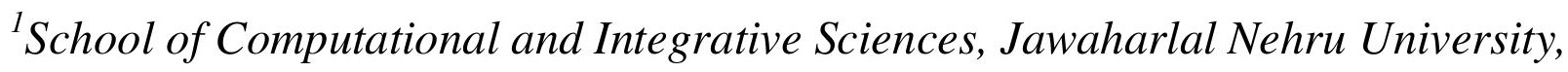
New Delhi, India

${ }^{2}$ Amity Institute of Biotechnology and Amity Institute of Integrative Sciences and Health, Amity University Haryana, Gurugram, India

\# contributed equally

*corresponding authors:

Atanu Banerjee; abanerjee1@ggn.amity.edu

Andrew M.Lynn; andrew@jnu.ac.in

Rajendra Prasad; rprasad@ggn.amity.edu 


\begin{abstract}
In view of the multiple clinical and physiological implications of $\mathrm{ABC}$ transporter proteins, there is a considerable interest among researchers to characterize them functionally. However, such characterizations are based on the premise that $\mathrm{ABC}$ proteins are accurately identified in the proteome of an organism, and their topology is correctly predicted. With this objective, we have developed ABC-finder, i.e., a Docker-based package for the identification of ABC proteins in all organisms, and visualization of the topology of $\mathrm{ABC}$ proteins using a web browser. $\mathrm{ABC}$-finder is built and deployed in a Linux container, making it scalable for many concurrent users on our servers and enabling users to download and run it locally. Overall, ABC-finder is a convenient, portable, and platform-independent tool for the identification and topology prediction of $\mathrm{ABC}$ proteins.
\end{abstract}

ABC-finder is accessible at http://abc-finder.osdd.jnu.ac.in

\title{
KEYWORDS
}

ABC proteins, Nucleotide-binding domains, Transmembrane domains, Docker, Reproducibility

\section{RUNNING TITLE}

ABC-finder web server 


\section{INTRODUCTION}

ABC proteins comprise one of the largest and most important protein families, most proteins being involved in active transport [1]. A typical ABC transporter is composed of a pair of nucleotide-binding domains (NBDs) and transmembrane domains (TMDs) [2]. While the NBDs are involved in fueling the transport process by means of ATP hydrolysis, the TMDs are responsible for substrate recognition and form the translocation channel [3]. NBDs have several conserved motifs, namely, Walker A, Walker B, Signature sequence (C-motif), H-loop, D-loop, and Q-loop [4]. Contrarily, the TMDs display poor conservation across different subfamilies. HUGO Gene Nomenclature Committee divided the ABC superfamily into 7 subfamilies from $\mathrm{ABCA}$ to $\mathrm{ABCG}$. This classification was later extended for non-mammalian proteins with the addition of the $\mathrm{ABCH}$ subfamily found in insects [5] and fishes [6,7], and the ABCI subfamily found in plants [8]. $\mathrm{ABC}$ transporters can function both as importers as well as exporters, however, the former is restricted only to bacteria and plants and mediate the uptake of various nutrients, micronutrients, and phytohormones, etc. [9]. On the other hand, the $\mathrm{ABC}$ exporters facilitate the extrusion of a wide spectrum of substrates including ions, lipids, peptides, toxic xenobiotics, etc. [10]. Numerous studies have suggested the role of ABC transporters in various human diseases and chemoresistance [1]. Besides their role as transporters, some ABC proteins harbor just the NBDs, for instance, the $\mathrm{ABCE}$ and $\mathrm{ABCF}$ family representatives, and have implications in ribosome biogenesis, translation control, etc. [11,12], further adding to the immense biological relevance of this superfamily. The primary requirement for in-depth investigations pertaining to $\mathrm{ABC}$ proteins is their accurate identification from the genome/proteome and analysis of its topology. Even though programs performing certain steps in isolation exist, there is a need for a unified package to do the job with lesser hassles and more emphasis on reproducibility, keeping in view that reproducibility of research is the key element in modern science [13]. In an effort to make a simpler program available to the biology researcher community, we herein present "ABC-finder" as a simple and fast tool for identification and topology prediction of $\mathrm{ABC}$ proteins based on our previously established pipeline which led to the inventorization of ABC proteins in a number of yeast species [14-16]. ABC-finder combines stand-out methodologies, namely profile-HMM and TOPCONS for homology detection, and prediction of the topology of membrane proteins, respectively in a seamless manner whereby the users need to provide only the organism's name or the proteome 
file as an input. Our analysis with reference organisms shows a strong correlation with the $\mathrm{ABC}$ protein inventories available in the literature.

\section{METHODOLOGIES AND WORKFLOW}

\section{Data submission}

Protein sequence data can be submitted in the following manner to the ABC-finder platform. The user can either specify the organism's name (Homo sapiens, Arabidopsis thaliana, or Candida glabrata) or can upload a raw FASTA file (uncompressed) of the proteome. The file size is, however, limited to $95 \mathrm{MB}$. In the last step, the user needs to provide an email address to get the result files directly delivered.

\section{Method}

\section{Prediction of potential ABC proteins based on NBD HMM}

To extract the putative $\mathrm{ABC}$ proteins from the sequence input, we utilized a protocol that was developed previously by us for inventorization of ABC proteins in yeasts [14-16]. Briefly, the HMM profile of the ABC-tran model (accession PF00005) obtained from the Pfam database [17] is used as a query to match against the proteome of an organism with the help of the "hmmsearch" function within the HMMER package [18] using the default settings. Positive hits above the default threshold are then further filtered based on a cutoff defined from the plot of domain-score and E-value. The default cut-off is system-generated from the E-value and requires manual filtering to remove proteins incorrectly classified above the cut-off. To automate this step, we use the observation that there is a small difference between the scores and E-values for proteins that belong to the same fold, but a large difference when scoring proteins from unrelated folds. This sudden drop in the sorted scores is exploited to mine proteins belonging to the defined class with minimal false positives.

\section{Clustering of sequences using Cd-hit}

Next, ABC-finder uses the Cluster Database at High Identity with Tolerance (Cd-hit) [19]. This clustering algorithm allows the grouping of all the sequences based on their sequence 
similarities. Given that Cd-hit clusters the highly similar (redundant) sequences, it allows the grouping of sequences resulting from different transcript variants of each $\mathrm{ABC}$ protein that usually populate the database in case of higher eukaryotes. The user also has the option to optimize the input parameters for the program from the "advanced options" menu.

\section{Prediction of the TMD and protein topology}

Since most of the families under the ABC superfamily include membrane transporters, it is relevant to detect their presence among putative proteins. Following the Cd-hit run, ABCfinder utilizes the stand-out program TOPCONS [20], which is a widely used program for consensus prediction of membrane protein topology. Once the TM helices are defined using TOPCONS, ABC-finder uses a set of in-house written Python scripts to demarcate the NBDs and TMDs in each of the predicted ABC proteins.

\section{Visualization}

E-value and domain score values of all the proteins above the inclusion threshold, as obtained from the HMM analysis are presented in the form of a plot. This plot allows the further filtering of sequences as defined in the "Prediction of potential ABC proteins based on NBD HMM" section. The arrangement of TMDs and NBDs as obtained with the help of TOPCONS is used to generate the final topology diagram of the proteins, respectively. Dynamic and Static plots are generated with Plotly (https://plot.ly/) and Orca (https://plot.ly/python/orcamanagement/). All the results files and several other log files are generated and zipped as the output data for downloading.

The overall workflow implemented in the ABC-finder server is shown in Figure 1. The help page on the web server provides a step-by-step guide to $\mathrm{ABC}$-finder. All results are kept on the server for ten days.

\section{IMPLEMENTATION}

ABC-finder server is implemented in Python 3.7.6 (http://www.python.org/) using the Web framework Django 3.0.3 (http://www.djangoproject.com/). The system is containerized using Docker 19.03.3 [21] and docker-compose 1.25.0. Job queuing is carried out by the asynchronous 
task queue Celery 3.0.19 that uses the distributed message passing system Redis 3.3.11.

Users can also install the ABC-finder web server directly from the source code or build and run it from within Docker container using the instructions provided in the Supplementary information. The Supplementary information also contains FAQs and some useful links.

\section{RESULTS AND DISCUSSION}

Once the input proteome file is uploaded or the organism is specified to ABC-finder, the server provides a zipped result folder that includes the following files in different formats (indicated within the parenthesis):

1. $\operatorname{search}(. \mathbf{f a a}) \rightarrow$ it is the proteome file that is submitted to ABC-finder for analysis. It is either uploaded by the user or retrieved by the web server depending upon the organism specified by the user.

2. profile $(. \mathbf{h m m}) \rightarrow$ it is the profile HMM derived from the PF00005 seed alignment.

3. hmm_output $\rightarrow$ it is the output obtained after running the "hmmsearch" function with the user-specified proteome file using profile.hmm as the query.

4. E-value_Domain_Score(.html/.pdf/.PNG/.SVG/.JPEG) $\rightarrow$ it is the plot of E-value and domain score for the sequences above the inclusion threshold as obtained from the hmm_output file. A representative plot for the analysis of S. cerevisiae proteome is provided in Figure 2.

5. threshold(.txt) $\rightarrow$ this file lists the IDs of the putative ABC protein candidates that are identified in the query proteome. These are predicted based on a cutoff defined from the plot of domain-score and E-value.

6. search_faa0(.clstr) $\rightarrow$ it is the output file obtained after running Cd-hit. It contains the different protein clusters based on sequence similarity. Users will need to refer to this file in special cases where multiple variants are reported for each protein in the database.

7. search_faa1(faa) $\rightarrow$ FASTA file utilized as the input for TOPCONS.

8. query.result(.txt) $\rightarrow$ it is the final output file obtained from TOPCONS.

9. Topology Plot(.html/.pdf/.PNG/.SVG/.JPEG) $\rightarrow$ this plot represents the topology of the identified $\mathrm{ABC}$ proteins. TOPCONS is utilized for the prediction of the transmembrane domains. A representative topology plot for the predicted $\mathrm{ABC}$ proteins 
in the S. cerevisiae S288C strain is provided in Figure 3. The topology plot should be referred alongside the Cd-hit output file "search_faa0.clstr" to detect the highly similar sequence clusters, especially in the case of higher eukaryotes, wherein sequences from all the transcript variants of each protein are present in the database.

To evaluate the performance of $\mathrm{ABC}$-finder, we utilized already reported inventories of $\mathrm{ABC}$ proteins from prokaryotic as well as eukaryotic systems. The results are summarized in Table 1. Overall, the results show a very good correlation with the number of $A B C$ proteins that are reported in the literature for the reference organisms.

Since the ABC-finder protocol uses relatively stringent parameters, the results obtained should reflect the most likely $\mathrm{ABC}$ candidate proteins in the user-specified proteome. To test this further, we analyzed the results for $S$. cerevisiae, most of whose $\mathrm{ABC}$ proteins are experimentally characterized. As per earlier studies, the organism comprises $30 \mathrm{ABC}$ proteins [22], 27 of which come with some degree of experimental characterization. As summarized in Table 2, ABC-finder could identify all 30 of the reported ABC proteins. In addition, it also identifies one uncharacterized protein YKR104W (NP_013030.1). Further sequence and structure-function analysis will help confirm its status as an $\mathrm{ABC}$ protein. Since, $\mathrm{ABC}$-finder utilizes TOPCONS, which combines an arbitrary number of topology predictions into one consensus prediction [20] and combines it with the results of HMM-based NBD-mapping. Hence, it presents a highly plausible domain(s) arrangement (topology) in ABC proteins (Figure 3). Furthermore, the Cd-hit aided clustering, which allows the grouping of the candidate proteins according to sequence similarity, can be exploited to classify the $\mathrm{ABC}$ members into various subfamilies.

Altogether, the web server caters to the $\mathrm{ABC}$ research community by providing a very simple tool that meets all the preliminary needs pertaining to sequence/domain analysis of the $\mathrm{ABC}$ proteins. Considering the need for analysis of larger datasets by some users, we have also made it feasible for the users to run $\mathrm{ABC}$-finder locally. Given the numerous physiological and clinical implications of $\mathrm{ABC}$ proteins across the living world, the web server is an extremely useful tool that will be further improvised in the subsequent versions.

\section{SOFTWARE AVAILABILITY}

The scripts we used to deploy the containers in our study are publicly available on GitHub and 
the Docker images are available on DockerHub.

GitHub URL (project home page for source code): https://github.com/lynngroup/abcfinder

DockerHub URL: https://hub.docker.com/r/lynngroup/abcfinder

\section{FUNDING}

$\mathrm{AB}$, AML, and RP are supported by funding from the Department of Biotechnology, Government of India, grant no. BT/PR32349/MED/29/1456/2019.

\section{ACKNOWLEDGEMENTS}

We are grateful to all our colleagues involved in testing the $\mathrm{ABC}$-finder web server. $\mathrm{AB}$ acknowledges funding support from SERB (SRG/2019/000514). PV and NKM are thankful to funding agencies ICMR and Department of Biotechnology (DBT/JRF/15/AL, DBT/2016/JNU/695), Govt. of India and JNU for financial support and fellowships. The authors acknowledge the High-Performance Computational Facility (HPCF) at SCIS, JNU.

\section{CONFLICT OF INTEREST}

None

\section{REFERENCES}

[1] C.F. Higgins, ABC transporters: physiology, structure and mechanism--an overview, Res. Microbiol. 152 (2001) 205-210. https://www.sciencedirect.com/science/article/pii/S0923250801011937.

[2] K.P. Locher, Mechanistic diversity in ATP-binding cassette (ABC) transporters, Nat. Struct. Mol. Biol. 23 (2016) 487-493. https://doi.org/10.1038/nsmb.3216.

[3] R. Prasad, A. Banerjee, N.K. Khandelwal, S. Dhamgaye, The ABCs of Candida albicans Multidrug Transporter Cdr1, Eukaryot. Cell. 14 (2015) 1154-1164. https://doi.org/10.1128/EC.00137-15.

[4] A. Moreno, A. Banerjee, R. Prasad, P. Falson, PDR-like ABC systems in pathogenic fungi, Res. Microbiol. 170 (2019) 417-425. https://doi.org/10.1016/j.resmic.2019.09.002.

[5] M. Dean, T. Annilo, Evolution of the ATP-binding cassette (ABC) transporter superfamily in vertebrates, Annu. Rev. Genomics Hum. Genet. 6 (2005) 123-142. https://doi.org/10.1146/annurev.genom.6.080604.162122.

[6] T. Luckenbach, S. Fischer, A. Sturm, Current advances on ABC drug transporters in fish, Comp. Biochem. Physiol. C. Toxicol. Pharmacol. 165 (2014) 28-52. 
https://doi.org/10.1016/j.cbpc.2014.05.002.

[7] M. Popovic, R. Zaja, J. Loncar, T. Smital, A novel ABC transporter: the first insight into zebrafish (Danio rerio) ABCH1, Mar. Environ. Res. 69 Suppl (2010) S11-3. https://doi.org/10.1016/j.marenvres.2009.10.016.

[8] P.J. Verrier, D. Bird, B. Burla, E. Dassa, C. Forestier, M. Geisler, M. Klein, Ü. Kolukisaoglu, Y. Lee, E. Martinoia, Others, Plant ABC proteins--a unified nomenclature and updated inventory, Trends Plant Sci. 13 (2008) 151-159. https://www.sciencedirect.com/science/article/pii/S1360138508000368.

[9] O. Lewinson, N. Livnat-Levanon, Mechanism of Action of ABC Importers: Conservation, Divergence, and Physiological Adaptations, J. Mol. Biol. 429 (2017) 606-619. https://doi.org/10.1016/j.jmb.2017.01.010.

[10] K. Beis, Structural basis for the mechanism of ABC transporters, Biochem. Soc. Trans. 43 (2015) 889-893. https://doi.org/10.1042/BST20150047.

[11] V. Murina, M. Kasari, H. Takada, M. Hinnu, C.K. Saha, J.W. Grimshaw, T. Seki, M. Reith, M. Putrinš, T. Tenson, H. Strahl, V. Hauryliuk, G.C. Atkinson, ABCF ATPases Involved in Protein Synthesis, Ribosome Assembly and Antibiotic Resistance: Structural and Functional Diversification across the Tree of Life, J. Mol. Biol. 431 (2019) 3568-3590. https://doi.org/10.1016/j.jmb.2018.12.013.

[12] V. Vasiliou, K. Vasiliou, D.W. Nebert, Human ATP-binding cassette (ABC) transporter family, Hum. Genomics. 3 (2009) 281-290. https://doi.org/10.1186/1479-7364-3-3-281.

[13] M. Baker, 1,500 scientists lift the lid on reproducibility, Nature. 533 (2016) 452-454. https://doi.org/10.1038/533452a.

[14] S. Kumari, M. Kumar, N.K. Khandelwal, P. Kumari, M. Varma, P. Vishwakarma, G. Shahi, S. Sharma, A.M. Lynn, R. Prasad, N.A. Gaur, ABC transportome inventory of human pathogenic yeast Candida glabrata: Phylogenetic and expression analysis, PLoS One. 13 (2018) e0202993. https://doi.org/10.1371/journal.pone.0202993.

[15] M. Wasi, N.K. Khandelwal, P. Vishwakarma, A.M. Lynn, A.K. Mondal, R. Prasad, Inventory of $\mathrm{ABC}$ proteins and their putative role in salt and drug tolerance in Debaryomyces hansenii, Gene. 676 (2018) 227-242. https://doi.org/10.1016/j.gene.2018.07.029.

[16] M. Wasi, N.K. Khandelwal, A.J. Moorhouse, R. Nair, P. Vishwakarma, G. Bravo Ruiz, Z.K. Ross, A. Lorenz, S.M. Rudramurthy, A. Chakrabarti, A.M. Lynn, A.K. Mondal, N.A.R. Gow, R. Prasad, ABC Transporter Genes Show Upregulated Expression in DrugResistant Clinical Isolates of Candida auris: A Genome-Wide Characterization of ATPBinding Cassette (ABC) Transporter Genes, Front. Microbiol. 10 (2019) 1445. https://doi.org/10.3389/fmicb.2019.01445.

[17] R.D. Finn, P. Coggill, R.Y. Eberhardt, S.R. Eddy, J. Mistry, A.L. Mitchell, S.C. Potter, M. Punta, M. Qureshi, A. Sangrador-Vegas, G.A. Salazar, J. Tate, A. Bateman, The Pfam protein families database: towards a more sustainable future, Nucleic Acids Res. 44 (2016) D279-85. https://doi.org/10.1093/nar/gkv1344.

[18] S.R. Eddy, A new generation of homology search tools based on probabilistic inference, Genome Inform. 23 (2009) 205-211. https://www.ncbi.nlm.nih.gov/pubmed/20180275.

[19] W. Li, A. Godzik, Cd-hit: a fast program for clustering and comparing large sets of protein or nucleotide sequences, Bioinformatics. 22 (2006) 1658-1659. https://doi.org/10.1093/bioinformatics/btl158.

[20] K.D. Tsirigos, C. Peters, N. Shu, L. Käll, A. Elofsson, The TOPCONS web server for 
consensus prediction of membrane protein topology and signal peptides, Nucleic Acids Res. 43 (2015) W401-7. https://doi.org/10.1093/nar/gkv485.

[21] C. Boettiger, An introduction to Docker for reproducible research, Oper. Syst. Rev. 49 (2015) 71-79. https://doi.org/10.1145/2723872.2723882.

[22] C.M. Paumi, M. Chuk, J. Snider, I. Stagljar, S. Michaelis, ABC transporters in Saccharomyces cerevisiae and their interactors: new technology advances the biology of the ABCC (MRP) subfamily, Microbiol. Mol. Biol. Rev. 73 (2009) 577-593. https://doi.org/10.1128/MMBR.00020-09.

[23] M. Dean, A. Rzhetsky, R. Allikmets, The human ATP-binding cassette (ABC) transporter superfamily, Genome Res. 11 (2001) 1156-1166. https://doi.org/10.1101/gr.184901.

[24] W. Dermauw, T. Van Leeuwen, The ABC gene family in arthropods: comparative genomics and role in insecticide transport and resistance, Insect Biochem. Mol. Biol. 45 (2014) 89-110. https://doi.org/10.1016/j.ibmb.2013.11.001.

[25] Z. Feng, D. Liu, L. Wang, Y. Wang, Z. Zang, Z. Liu, B. Song, L. Gu, Z. Fan, S. Yang, J. Chen, Y. Cui, A Putative Efflux Transporter of the ABC Family, YbhFSR, in Escherichia coli Functions in Tetracycline Efflux and $\mathrm{Na}+(\mathrm{Li}+) / \mathrm{H}+$ Transport, Front. Microbiol. 11 (2020) 556. https://doi.org/10.3389/fmicb.2020.00556.

[26] Y. Kim, S.-Y. Park, D. Kim, J. Choi, Y.-H. Lee, J.-H. Lee, W. Choi, Genome-scale analysis of $\mathrm{ABC}$ transporter genes and characterization of the $\mathrm{ABCC}$ type transporter genes in Magnaporthe oryzae, Genomics. 101 (2013) 354-361. https://doi.org/10.1016/j.ygeno.2013.04.003.

[27] J.A. Sheps, S. Ralph, Z. Zhao, D.L. Baillie, V. Ling, The ABC transporter gene family of Caenorhabditis elegans has implications for the evolutionary dynamics of multidrug resistance in eukaryotes, Genome Biol. 5 (2004) R15. https://doi.org/10.1186/gb-2004-5-3r15.

[28] P. Leprohon, D. Légaré, I. Girard, B. Papadopoulou, M. Ouellette, Modulation of Leishmania ABC protein gene expression through life stages and among drug-resistant parasites, Eukaryot. Cell. 5 (2006) 1713-1725. https://doi.org/10.1128/EC.00152-06.

[29] O. Garcia, P. Bouige, C. Forestier, E. Dassa, Inventory and comparative analysis of rice and Arabidopsis ATP-binding cassette (ABC) systems, J. Mol. Biol. 343 (2004) 249-265. https://doi.org/10.1016/j.jmb.2004.07.093.

[30] K. Gulshan, W.S. Moye-Rowley, Vacuolar import of phosphatidylcholine requires the ATP-binding cassette transporter Ybt1, Traffic. 12 (2011) 1257-1268. https://doi.org/10.1111/j.1600-0854.2011.01228.x.

[31] D. Wawrzycka, I. Sobczak, G. Bartosz, T. Bocer, S. Ułaszewski, A. Goffeau, Vmr 1p is a novel vacuolar multidrug resistance ABC transporter in Saccharomyces cerevisiae, FEMS Yeast Res. 10 (2010) 828-838. https://doi.org/10.1111/j.1567-1364.2010.00673.x.

[32] N.C. Rockwell, H. Wolfger, K. Kuchler, J. Thorner, ABC transporter Pdr10 regulates the membrane microenvironment of Pdr12 in Saccharomyces cerevisiae, J. Membr. Biol. 229 (2009) 27-52. https://doi.org/10.1007/s00232-009-9173-5.

[33] S. Petrovic, L. Pascolo, R. Gallo, F. Cupelli, J.D. Ostrow, A. Goffeau, C. Tiribelli, C.V. Bruschi, The products of YCF1 and YLL015w (BPT1) cooperate for the ATP-dependent vacuolar transport of unconjugated bilirubin in Saccharomyces cerevisiae, Yeast. 16 (2000) 561-571. https://doi.org/3.0.CO;2-L."> 10.1002/(SICI)1097-0061(200004)16:6<561::AIDYEA551>3.0.CO;2-L.

[34] H. Wolfger, Y.M. Mamnun, K. Kuchler, The Yeast Pdr15p ATP-binding Cassette (ABC) 
Protein Is a General Stress Response Factor Implicated in Cellular Detoxification, Journal of Biological Chemistry. 279 (2004) 11593-11599.

https://doi.org/10.1074/jbc.m311282200.

[35] J. Golin, S.V. Ambudkar, M.M. Gottesman, A.D. Habib, J. Sczepanski, W. Ziccardi, L. May, Studies with novel Pdr5p substrates demonstrate a strong size dependence for xenobiotic efflux, J. Biol. Chem. 278 (2003) 5963-5969.

https://doi.org/10.1074/jbc.M210908200.

[36] P. Piper, Y. Mahé, S. Thompson, R. Pandjaitan, C. Holyoak, R. Egner, M. Mühlbauer, P. Coote, K. Kuchler, The pdr12 ABC transporter is required for the development of weak organic acid resistance in yeast, EMBO J. 17 (1998) 4257-4265. https://doi.org/10.1093/emboj/17.15.4257.

[37] J. Servos, E. Haase, M. Brendel, Gene SNQ2 of Saccharomyces cerevislae, which confers resistance to 4-nitroquinoline-N-oxide and other chemicals, encodes a $169 \mathrm{kDa}$ protein homologous to ATP-dependent permeases, Molecular and General Genetics MGG. 236-236 (1993) 214-218. https://doi.org/10.1007/bf00277115.

[38] T.R. Cabrito, M.C. Teixeira, A. Singh, R. Prasad, I. Sá-Correia, The yeast ABC transporter Pdr18 (ORF YNR070w) controls plasma membrane sterol composition, playing a role in multidrug resistance, Biochem. J. 440 (2011) 195-202. https://doi.org/10.1042/BJ20110876.

[39] A. Decottignies, A.M. Grant, J.W. Nichols, H. de Wet, D.B. McIntosh, A. Goffeau, ATPase and multidrug transport activities of the overexpressed yeast ABC protein Yor1p, J. Biol. Chem. 273 (1998) 12612-12622. https://doi.org/10.1074/jbc.273.20.12612.

[40] M. Papay, C. Klein, I. Hapala, L. Petriskova, K. Kuchler, M. Valachovic, Mutations in the nucleotide-binding domain of putative sterol importers Aus1 and Pdr11 selectively affect utilization of exogenous sterol species in yeast, Yeast. 37 (2020) 5-14. https://doi.org/10.1002/yea.3456.

[41] S. Michaelis, STE6, the yeast a-factor transporter, Semin. Cell Biol. 4 (1993) 17-27. https://doi.org/10.1006/scel.1993.1003.

[42] V. Kasari, A.A. Pochopien, T. Margus, V. Murina, K. Turnbull, Y. Zhou, T. Nissan, M. Graf, J. Nováček, G.C. Atkinson, M.J.O. Johansson, D.N. Wilson, V. Hauryliuk, A role for the Saccharomyces cerevisiae ABCF protein New1 in translation termination/recycling, Nucleic Acids Res. 47 (2019) 8807-8820. https://doi.org/10.1093/nar/gkz600.

[43] K. Kiriyama, K.Y. Hara, A. Kondo, Extracellular glutathione fermentation using engineered Saccharomyces cerevisiae expressing a novel glutathione exporter, Appl. Microbiol. Biotechnol. 96 (2012) 1021-1027. https://doi.org/10.1007/s00253-012-4075-3.

[44] C.B.F. Andersen, T. Becker, M. Blau, M. Anand, M. Halic, B. Balar, T. Mielke, T. Boesen, J.S. Pedersen, C.M.T. Spahn, T.G. Kinzy, G.R. Andersen, R. Beckmann, Structure of eEF3 and the mechanism of transfer RNA release from the E-site, Nature. 443 (2006) 663-668. https://doi.org/10.1038/nature05126.

[45] K. Gościńska, S. Shahmoradi Ghahe, S. Domogała, U. Topf, Eukaryotic Elongation Factor 3 Protects Saccharomyces cerevisiae Yeast from Oxidative Stress, Genes . 11 (2020). https://doi.org/10.3390/genes11121432.

[46] C.W.T. van Roermund, L. IJlst, A. Baker, R.J.A. Wanders, F.L. Theodoulou, H.R. Waterham, The Saccharomyces cerevisiae ABC subfamily D transporter Pxa1/Pxa2p coimports CoASH into the peroxisome, FEBS Lett. (2020). https://febs.onlinelibrary.wiley.com/doi/abs/10.1002/1873-3468.13974. 
[47] A. Zutz, S. Gompf, H. Schägger, R. Tampé, Mitochondrial ABC proteins in health and disease, Biochim. Biophys. Acta. 1787 (2009) 681-690.

https://doi.org/10.1016/j.bbabio.2009.02.009.

[48] D. Lockshon, L.E. Surface, E.O. Kerr, M. Kaeberlein, B.K. Kennedy, The sensitivity of yeast mutants to oleic acid implicates the peroxisome and other processes in membrane function, Genetics. 175 (2007) 77-91. https://doi.org/10.1534/genetics.106.064428.

[49] C.R.V. de Aldana, C.R.V. de Aldana, M.J. Marton, A.G. Hinnebusch, GCN20, a novel ATP binding cassette protein, and GCN1 reside in a complex that mediates activation of the eIF2 alpha kinase GCN2 in amino acid-starved cells, The EMBO Journal. 14 (1995) 31843199. https://doi.org/10.1002/j.1460-2075.1995.tb07321.x.

[50] L. Young, K. Leonhard, T. Tatsuta, J. Trowsdale, T. Langer, Role of the ABC transporter Md11 in peptide export from mitochondria, Science. 291 (2001) 2135-2138. https://doi.org/10.1126/science.1056957.

[51] V. Srinivasan, A.J. Pierik, R. Lill, Crystal structures of nucleotide-free and glutathionebound mitochondrial ABC transporter Atm1, Science. 343 (2014) 1137-1140. https://doi.org/10.1126/science.1246729.

[52] J. Dong, R. Lai, J.L. Jennings, A.J. Link, A.G. Hinnebusch, The novel ATP-binding cassette protein ARB1 is a shuttling factor that stimulates $40 \mathrm{~S}$ and $60 \mathrm{~S}$ ribosome biogenesis, Mol. Cell. Biol. 25 (2005) 9859-9873. https://doi.org/10.1128/MCB.25.22.9859-9873.2005.

[53] A. Yarunin, V.G. Panse, E. Petfalski, C. Dez, D. Tollervey, E.C. Hurt, Functional link between ribosome formation and biogenesis of iron-sulfur proteins, EMBO J. 24 (2005) 580-588. https://doi.org/10.1038/sj.emboj.7600540.

[54] H.-Y. Liu, Y.-C. Chiang, J. Pan, J. Chen, C. Salvadore, D.C. Audino, V. Badarinarayana, V. Palaniswamy, B. Anderson, C.L. Denis, Characterization of CAF4 and CAF16 Reveals a Functional Connection between the CCR4-NOT Complex and a Subset of SRB Proteins of the RNA Polymerase II Holoenzyme, Journal of Biological Chemistry. 276 (2001) 75417548. https://doi.org/10.1074/jbc.m009112200. 


\section{TABLES}

Table 1: A comparison between the number of $A B C$ proteins reported in the literature $\mathrm{v} / \mathrm{s}$ predicted by $\mathrm{ABC}$-finder. cd-hit parameter used: $\mathbf{- c}=$ sequence identity threshold; $\mathbf{- n}=$ word length; Default $=(-\mathrm{c}=0.9 ;-\mathrm{n}=5)$. Result files for all the below mentioned organisms are available at https://zenodo.org/record/4603195.

\begin{tabular}{|c|c|c|c|c|c|}
\hline S. no. & $\begin{array}{l}\text { Organism } \\
\text { name }\end{array}$ & $\begin{array}{l}\text { ABC } \\
\text { proteins } \\
\text { reported } \\
\text { [literature } \\
\text { reference] }\end{array}$ & $\begin{array}{l}\text { ABC } \\
\text { proteins } \\
\text { predicted } \\
\text { by } \quad \mathrm{ABC} \text { - } \\
\text { finder }\end{array}$ & $\begin{array}{l}\text { Cd-hit } \\
\text { parameter used }\end{array}$ & $\begin{array}{l}\text { Match percent } \\
\text { (between the literature } \\
\text { reported and } \mathrm{ABC} \text { - } \\
\text { finder reported } \\
\text { numbers) }\end{array}$ \\
\hline 1 & Homo sapiens & $\begin{array}{l}48-49 \\
{[12,23]}\end{array}$ & 48 & -c $0.6-\mathrm{n} 4$ & 100 \\
\hline 2 & $\begin{array}{l}\text { Drosophila } \\
\text { melanogaster }\end{array}$ & $56[24]$ & 55 & Default & 98 \\
\hline 3 & $\begin{array}{l}\text { Escherichia } \\
\text { coli }\end{array}$ & 79 [25] & 77 & Default & 97 \\
\hline 4 & $\begin{array}{l}\text { Saccharomyces } \\
\text { cerevisiae }\end{array}$ & $30[22]$ & 31 & Default & 97 \\
\hline 5 & $\begin{array}{l}\text { Candida } \\
\text { glabrata }\end{array}$ & 25 [14] & 25 & Default & 100 \\
\hline 6 & Candida auris & 28 [16] & 28 & Default & 100 \\
\hline
\end{tabular}




\begin{tabular}{|c|c|c|c|c|c|}
\hline 7 & $\begin{array}{l}\text { Debaryomyces } \\
\text { hansenii }\end{array}$ & 30 [15] & 30 & Default & 100 \\
\hline 8 & $\begin{array}{l}\text { Magnaporthe } \\
\text { oryzae }\end{array}$ & $50[26]$ & 50 & -c 1 -n 5 & 100 \\
\hline 9 & $\begin{array}{l}\text { Caenorhabditis } \\
\text { elegans }\end{array}$ & 60 [27] & 56 & Default & 93 \\
\hline 10 & $\begin{array}{l}\text { Leishmania } \\
\text { major }\end{array}$ & $42[28]$ & 41 & -c 1 -n 5 & 98 \\
\hline 11 & Bombyx mori & $53-55$ [24] & 53 & Default & 100 \\
\hline 12 & Oryza sativa & $121[29]$ & 111 & -c 1 -n 5 & 92 \\
\hline 13 & $\begin{array}{l}\text { Arabidopsis } \\
\text { thaliana }\end{array}$ & 120 [29] & 121 & Default & 99 \\
\hline
\end{tabular}

Table 2: List of $\mathrm{ABC}$ proteins predicted by $\mathrm{ABC}$-finder in the $S$. cerevisiae $\mathrm{S} 288 \mathrm{C}$ proteome. NP_013030.1 has not been reported in previous inventories of S. cerevisiae ABC proteins.

\begin{tabular}{|l|l|l|l|}
\hline S.no. & Sequence ID & Protein details & $\begin{array}{l}\text { Literature } \\
\text { confirming } \\
\text { status as } \\
\text { ABC } \\
\text { protein }\end{array}$ \\
\hline 1 & NP_013052.1 & bile acid-transporting ATPase YBT1 & {$[30]$} \\
\hline
\end{tabular}




\begin{tabular}{|c|c|c|c|}
\hline 2 & NP_011828.1 & $\begin{array}{l}\text { putative ATP-binding cassette multidrug transporter } \\
\text { VMR1 }\end{array}$ & {$[31]$} \\
\hline 3 & NP_014973.1 & ATP-binding cassette multidrug transporter PDR10 & {$[32]$} \\
\hline 4 & NP_013086.1 & ATP-binding cassette bilirubin transporter BPT1 & {$[33]$} \\
\hline 5 & NP_010694.1 & ATP-binding cassette multidrug transporter PDR15 & {$[34]$} \\
\hline 6 & NP_014796.3 & ATP-binding cassette multidrug transporter PDR5 & {$[35]$} \\
\hline 7 & NP_010419.3 & $\begin{array}{l}\text { ATP-binding cassette glutathione S-conjugate } \\
\text { transporter YCF1 }\end{array}$ & {$[33]$} \\
\hline 8 & NP_015267.1 & ATP-binding cassette multidrug transporter PDR12 & {$[36]$} \\
\hline 9 & NP_010294.1 & ATP-binding cassette transporter SNQ2 & {$[37]$} \\
\hline 10 & NP_014468.3 & ATP-binding cassette multidrug transporter PDR18 & {$[38]$} \\
\hline 11 & NP_011797.3 & ATP-binding cassette transporter YOR1 & {$[39]$} \\
\hline 12 & NP_012252.1 & ATP-binding cassette multidrug transporter PDR11 & {$[40]$} \\
\hline 13 & NP_014654.1 & ATP-binding cassette sterol transporter AUS1 & {$[40]$} \\
\hline 14 & NP_014567.2 & uncharacterized protein YOL075C & - \\
\hline
\end{tabular}




\begin{tabular}{|c|c|c|c|}
\hline 15 & NP_012713.1 & ATP-binding cassette a-factor transporter STE6 & {$[41]$} \\
\hline 16 & NP_013029 & putative multidrug transporter NFT1 & - \\
\hline 17 & NP_015098.1 & New1 & [42] \\
\hline 18 & NP_009937.2 & putative ATP-dependent permease ADP1 & {$[43]$} \\
\hline 19 & NP_013350.1 & translation elongation factor EF-3 (YEF3) & {$[11,44]$} \\
\hline 20 & NP_014384.3 & translation elongation factor EF-3 (HEF3) & {$[11,45]$} \\
\hline 21 & NP_015178.1 & $\begin{array}{l}\text { ATP-binding cassette long-chain fatty acid transporter } \\
\text { PXA1 }\end{array}$ & {$[46]$} \\
\hline 22 & NP_012733.1 & $\begin{array}{l}\text { ATP-binding cassette long-chain fatty acid transporter } \\
\text { PXA2 }\end{array}$ & {$[46]$} \\
\hline 23 & NP_015053.2 & ATP-binding cassette permease MDL2 & {$[47,48]$} \\
\hline 24 & NP_116664.1 & putative AAA family ATPase GCN20 & [49] \\
\hline 25 & NP_013289.1 & ATP-binding cassette permease MDL1 & {$[50]$} \\
\hline 26 & NP_014030.1 & $\begin{array}{l}\text { ATP-binding cassette Fe/S cluster precursor transporter } \\
\text { ATM1 }\end{array}$ & {$[51]$} \\
\hline 27 & NP_010953.1 & ATP-binding cassette family ATPase ARB1 & {$[52]$} \\
\hline
\end{tabular}


bioRxiv preprint doi: https://doi.org/10.1101/2020.11.18.042887; this version posted April 29, 2021. The copyright holder for this preprint (which

was not certified by peer review) is the author/funder, who has granted bioRxiv a license to display the preprint in perpetuity. It is made available under aCC-BY 4.0 International license.

\begin{tabular}{|l|l|l|l|}
\hline 28 & NP_010376.3 & Fe-S cluster-binding ribosome biosynthesis protein RL1 & [53] \\
\hline 29 & NP_010346.3 & uncharacterized protein YDR061W & - \\
\hline $\mathbf{3 0}$ & NP_013030.1 & uncharacterized protein YKR104W & - \\
\hline 31 & NP_116625.1 & putative ATP-binding cassette family ATPase CAF16 & [54] \\
\hline
\end{tabular}




\section{FIGURE LEGENDS}

Figure 1: Generalized workflow of ABC-finder.

Figure 2: Plot of E-value and domain score of the sequences above the inclusion threshold value obtained after running the "hmmsearch" function with the S. cerevisiae S288C proteome.

Figure 3: Plot representing the topology of the predicted $\mathrm{ABC}$ proteins in the $S$. cerevisiae S288C strain. While the $\mathrm{x}$-axis denotes the amino acid number, the $\mathrm{y}$-axis denotes the sequence IDs. TOPCONS is utilized for the prediction of the transmembrane domains. Red columns represent transmembrane domains and blue spheres represent the nucleotide binding domains. 


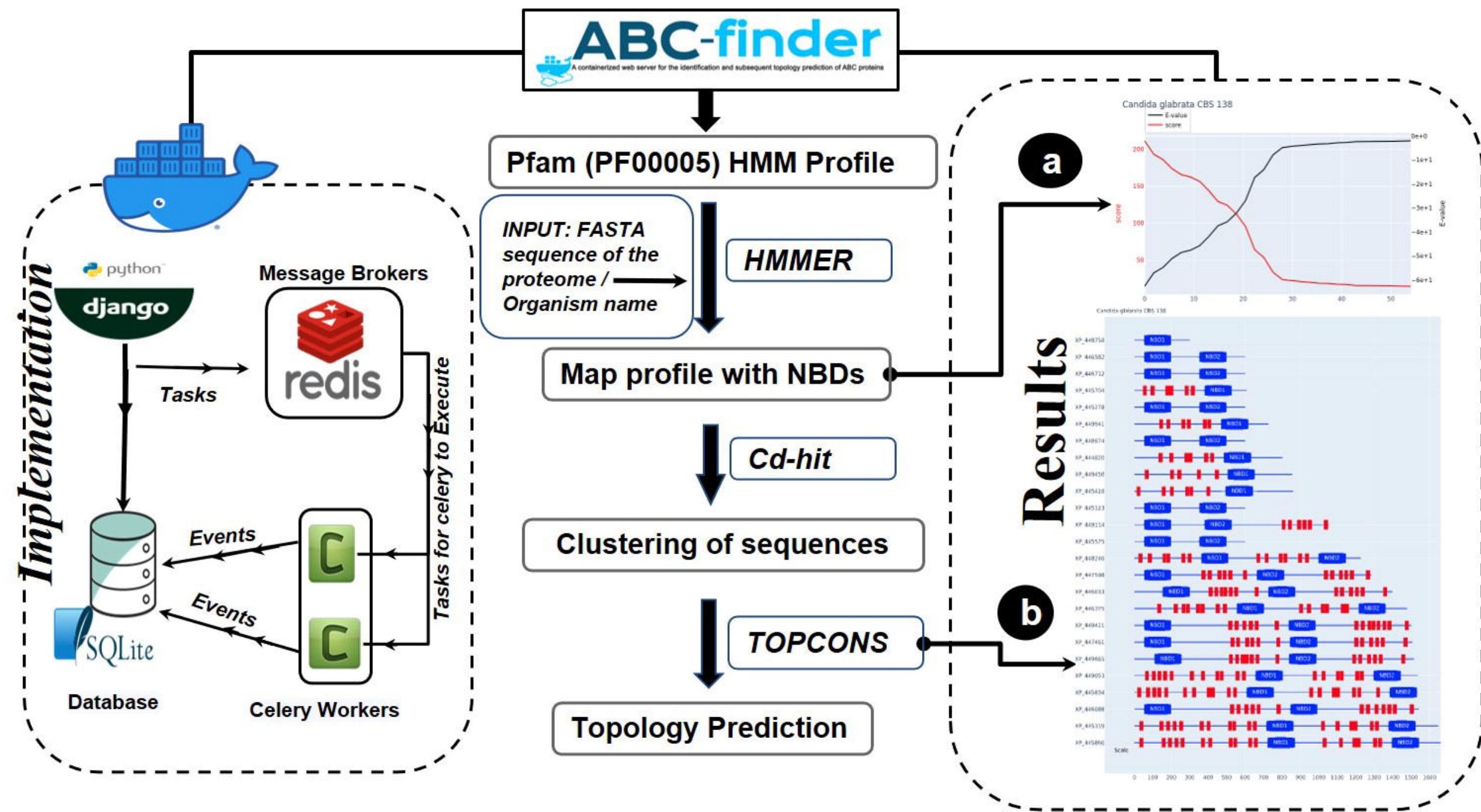


Saccharomyces cerevisiae S288C

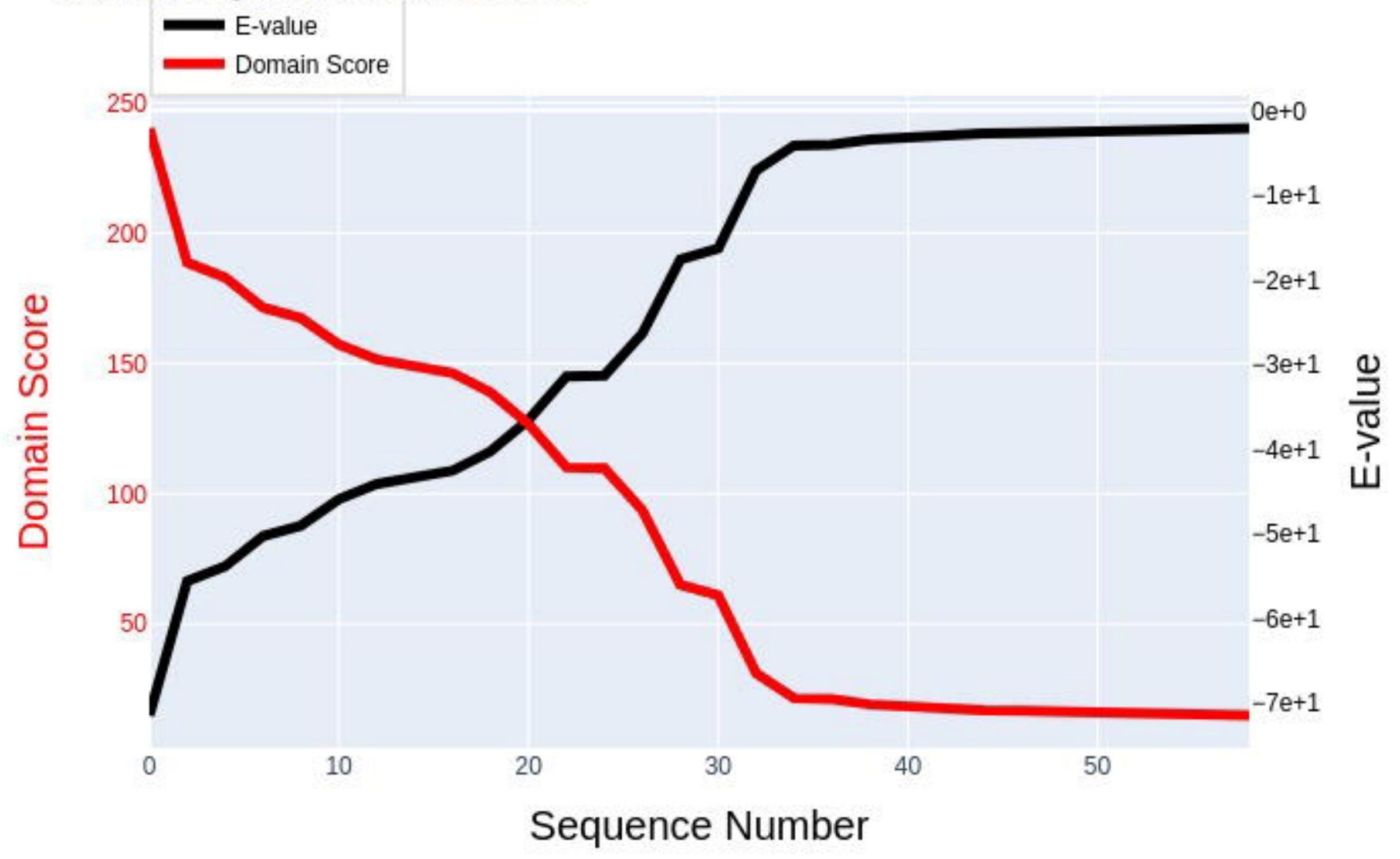




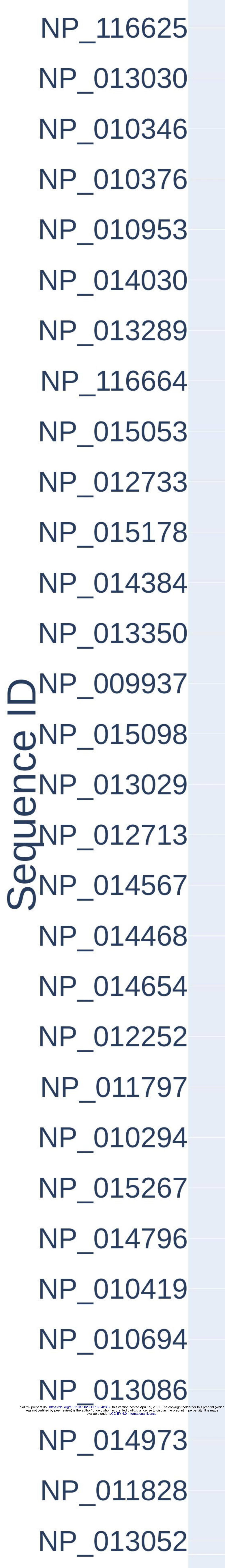



-Transmembrane helix -Nucleotide Binding Domains 